\title{
CALCULATION-EXPERIMENTAL METHOD OF RESEARCH IN A METALLIC CONDUCTOR WITH THE PULSE CURRENT OF ELECTRONIC WAVEPACKAGES AND DE BROGLIE ELECTRONIC HALF-WAVES
}

Purpose. Development of calculation-experimental method for a discovery and study of electronic wavepackages (EWP) and of de Broglie electronic half-waves in a metallic conductor with the pulse axial-flow current of high density. Methodology. Theoretical bases of the electrical engineering, bases of quantum physics, electrophysics bases of technique of high voltage and large pulse currents, and also bases of technique of measuring of permanent and variable electric value. Results. On the basis of generalization of results of research of features of the longitudinal wave periodic distributing of negatively charged transmitters of electric current of conductivity in the thin round continuous zincked steel wire offered and approved in the conditions of high-voltage laboratory method for a discovery and direct determination in him of geometrical parameters of "hot" and "cold" longitudinal areas quantized periodic longitudinal EWP and accordingly the mediated determination of values of the quantized lengths formative their de Broglie electronic half-waves. It is shown that results of close quantum mechanical calculations of EWP and quantized lengths $\lambda_{\text {enz }} / 2$ of longitudinal de Broglie halfwaves for the probed wire long $l_{0}$ well comport with the results of the executed high temperature experiments on the powerful high-voltage generator of homopolar large pulse current of millisecond duration. Originality. First calculationexperimental a way the important for the theory of electricity fact of existence is set in a round metallic explorer with the impulsive axial-flow current of the quantized coherent de Broglie electronic half-waves, amplitudes of which at the quantum number of $n=1,3,9$ correspond the middles of "hot» longitudinal areas of EWP. Calculation quantum mechanical correlation of type of $\lambda_{\text {enz }} / 2=l_{0} / n$ got experimental confirmation, in obedience to which on length of $l_{0}$ conductor the integer of quantized electronic half-waves is always laid de Broglie. Practical value. The use of the offered method allows to expose electro-technological possibilities of practical application of features sharply not homogeneous periodic wave longitudinal distributing of drifting lone electrons and accordingly by them the conditioned thermal field in round metallic conductors with the electric axial-flow current of high-slay. References 21 , figures 8.

Key words: metallic conductor, pulse current, electronic wavepackage, de Broglie electronic half-wave, calculationexperimental investigation of electronic processes in the conductor.

Описан расчетно-экспериментальный метод для обнаружения и изучения в электропроводящей макроструктуре металлического проводника с импульсным аксиальным током больиой плотности квантованных (с квантовым числом $n=1,2,3, \ldots)$ макроскопических «горячих» иириной $\Delta z_{n h}$ и «холодных» иириной $\bar{z}_{\text {псі }}$ продольных участков, образующих шаг шириной $\left(\Delta z_{n h}+\Delta z_{n c i}\right)$ периодически размещенных вдоль проводника квантованных продольных волновых электронных пакетов (ВЭП). Показано, что при протекании в круглом сплочном стальном оцинкованном проводе радиусом $r_{0}=0,8$ мм и длиной $l_{0}=320$ мм апериодического импульса тока временной формы $t_{m} / \tau_{p} \approx 9$ мс/160 мс с амплитудой его плотности $\delta_{0 m} \approx 0,37$ кA/мм² в исследуемом проводе стохастическим путем от одного протекания по нему указанного тока к другому возникают квантованные продольные ВЭП, имеющие один (п=1), три $(n=3)$ и девять $(n=9)$ «горячих» продольных участков одинаковой ширины $z_{n h}$. Места расположения середин данных «горячих" продольных участков ВЭП иириной $\Delta z_{n h} \approx 7$ мм вдоль провода соответствуют амплитудам распространяющихся вдоль него квантованных электронных полуволн де Бройля, характеризующихся в проведенных экспериментах квантовым числом $n=1,3,9$ и квантованной длиной полуволны $\lambda_{\text {епz }} / 2 \approx l_{0} / n$, равной 320,107 и 34 мм соответственно. Полученные экспериментальные результаты соответствуют расчетным квантовомеханическим данным применительно к дрейфующим свободным электронам электропроводящего материала провода, базирующимся на фундаментальном соотношении неопределенности Гейзенберга и установленных закономерностях волнового продольного распределения в структуре провода этих электронов. Библ. 21 , рис. 8 . Ключевые слова: металлический проводник, импульсный ток, волновой электронный пакет, электронная полуволна де Бройля, расчетно-экспериментальное исследование электронных процессов в металле.

Introduction. In [1-9] presented the results of many years of theoretical and experimental studies to establish the basic laws of quantum mechanical wave longitudinal and radial distributions drift of free electrons in the nonmagnetic metal circular solid cylindrical conductor of radius $r_{0}$ and length $l_{0}>r_{0}$ in which longitudinally runs pulse axial current $i_{0}(t)$ of arbitrary amplitude-time parameters (ATP). These results were obtained under the condition $\Delta_{i} / r_{0}>>1$, where $\Delta_{i}$ is the thickness of the skin layer of the current in the conductor, and its use in the averaged current density $\delta_{0}(t) \approx i_{0}(t) / S_{0}$, where $S_{0}=\pi r_{0}^{2}$ is the cross section of mentioned conductor. The results obtained in [1-9] data show that in a homogeneous conductive metal conductor structure comprising quantum number $n=1,2,3 \ldots$ of de Broglie electronic half-waves there are stochastic by longitudinal and radial quantized periodic electronic wavepackets (EWP) each of which contains one relatively «hot» and «cold» areas of the longitudinal or radial macroscopic dimensions. These sites give rise to a metal conductor macrostructure inhomogeneous temperature fields, periodically changing along its length 
or radius. Moreover, the temperature levels in the «hot» and «cold» longitudinal sections conductor at the manifestation of it EWP may vary up to 3.5 times [4, 7]. The stochastic nature of the formation of the quantized data is determined by EWP quantized energy states of free electrons trapped in the microstructure of the conductor material at the time of supplying a voltage and start the flow of electric current through it or that kind [6]. We point out that the wave packets, resulting in the propagation of monochromatic electromagnetic waves in dielectric media, at one time have been described in the theory of electromagnetism and today electrophysics they studied well enough [10] as for the EWP metallic conductors with an electrical DC, AC and pulse current of different ATP formed in electrically conductive structures with their drifting free electrons as a result of the interference (superposition) of coherent electronic half-waves of de Broglie, they are currently in the theory of electricity are practically unexplored. That's why so far quantumphysical features of the spatial distribution of the main carriers of electricity in these structures - drift of free electrons, manifested most dramatically in the case of occurrence on them in regular (high-current discharges in circuits of high-voltage electrical installations [7, 11]), abnormal and emergency operating modes (overcurrent, short-circuit and direct linear lightning strikes [8, 12]) of high current density $\left(10^{8} \mathrm{~A} / \mathrm{m}^{2}\right.$ or more $)$, and thus new areas of application in electrotechnology remain poorly understood. In this context, the development and practical use of new computational and experimental methods for the detection and study of quantized periodic EWP and quantized electronic half-waves of de Broglie in metal conductors with said electrical conduction current densities are actual scientific and technical problems.

The goal of the paper is development of computational and experimental method for the detection and study of quantized EWP and de Broglie electron halfwaves in the metal conductor with a high density pulsed axial current.

1. Problem definition of investigation of EWP and de Broglie electron half-waves in the metal conductor with pulse current. Consider still housed outdoors straight round solid non-magnetic metallic conductor radius $r_{0}$ and $l_{0}>>r_{0}$ length. Let air environment parameters correspond to normal atmospheric conditions (air pressure is $1.013 \cdot 10^{5} \mathrm{~Pa}$ and its temperature $T_{0}$ is $0{ }^{\circ} \mathrm{C}$ [10]), and the opposite ends of the conductor under consideration with the conductivity material $\gamma_{0}$ its electrical potential difference is applied, in varying unipolarly time $t$ by an arbitrary law. We suppose that on the test conductor cross-section $S_{0}=\pi r_{0}{ }^{2}$ along its longitudinal axis takes pulse unipolar conduction current $i_{0}(t)$ of amplitude $I_{0 m}$ characterized by the average density of $\delta_{0}(t)$. We restrict ourselves to the case for which the thickness of the skin layer of the current $\Delta_{i}$ in the conductor material substantially greater than its radius $r_{0}$. For an approximate description of the behavior of drifting free conductor of electrons, as in [1-9], we use the well-known one-electron approximation, neglect their mutual influence on each other, as well as the influence of the crystal lattice of the metal ion conductor on his itinerant electrons [10]. We adhere to the view that the longitudinal (radial) distribution of free electrons drifting in the test conductor subject to temporary Schrödinger wave equation, and according to their own quantized decisions [10]. It required on the basis of generalization obtained earlier in [1-9] quantum mechanical results concerning the electrical characteristics of the wave carrier distribution in the conduction current uniform conductive structures to formulate and test the in vitro methods to assess research EWP and electronic half-waves of de Broglie in thin circular metallic conductors with pulsed axial current $i_{0}(t)$ aperiodic temporary shape and high density $\delta_{0}(t)$.

2. A proposed method of detection in metal conductor with a pulse current of EWP and de Broglie electronic half-waves. For clarity and better understanding of the problem under consideration electrophysical give first approximate quantum mechanical ratio for the smallest width $\Delta z_{n h}$ «hot» longitudinal section through a conducting wire structure with pulsed axial current $i_{0}(t)$ causing the appearance in it the average current density with amplitude $\delta_{0 m} \approx I_{0 m} / S_{0}[7,9]$ :

$$
\Delta z_{n h} \approx e_{0} n_{e 0} h\left(m_{e} \delta_{0 m}\right)^{-1}\left[8+(\pi-2)^{2}\right]^{-1},
$$

where $e_{0}=1.602 \cdot 10^{-19} \mathrm{C}$ is the module of the electron electric charge [10]; $m_{e}=9.109 \cdot 10^{-31} \mathrm{~kg}$ is the electron rest mass [10]; $n_{e 0}$ is the average density of free electrons in the metal conductor to the test exposure to the electric current pulse $[10] ; h=6.626 \cdot 10^{-34} \mathrm{~J} \cdot \mathrm{s}$ is the Plank constant [10].

From (1) obtained using the fundamental Heisenberg uncertainty relation [10], it follows that the width of $\Delta z_{n h}$ «hot» longitudinal portion of the conductor is practically determined by the numerical value of the amplitude of the pulse current density $\delta_{0 m}$ in his material. So, taking into account (1) for copper conductor $\left(n_{e 0}=16.86 \cdot 10^{28} \mathrm{~m}^{-3}[10]\right)$ at $\delta_{0 m}=4 \cdot 10^{6} \mathrm{~A} / \mathrm{m}^{2}$ typical for normal operation of industrial electric alternating current networks [13], we find that it $\Delta z_{n h}$ width is approximately equal to $0.53 \mathrm{~m}$. At $\delta_{0 m}=4 \cdot 10^{8} \mathrm{~A} / \mathrm{m}^{2}$ corresponding to the emergency mode of operation of industrial electric networks with the flow of their current distributors fault currents [13] or the normal operation of high-current circuits of high-voltage electro installations [11], the estimated width $\Delta z_{n h}$ takes the numerical value of about $5.3 \mathrm{~mm} . \delta_{0 m}=4 \cdot 10^{11} \mathrm{~A} / \mathrm{m}^{2}$ which is characteristic for a quick electric explosion (EE) of thin metal wires [14] the width $\Delta z_{n h}$ «hot» longitudinal section in a copper conductor according to (1) is numerically equal to about $5.3 \mu \mathrm{m}$. Such microscopic value of $\Delta z_{n h}$ is in good agreement with the linear dimensions of the conductive fine fractions resulting from EE (sublimation of conductive parts) of thin metal wires $[11,14]$. In addition, according to [15] in the experimental study of the phenomenon of rapid $\mathrm{EE}$ in the air thin round copper wires $60 \mathrm{~mm}$ long and $100 \mathrm{~mm}$ in diameter by passing them from the high-voltage generator of pulse currents (GPC) sinusoidal decaying exponentially bit high density pulse current $\left(\delta_{0 m} \approx 6.4 \cdot 10^{12} \mathrm{~A} / \mathrm{m}^{2}\right)$ dispersed in the products the 
explosive destruction of solid copper (in the «metal» plasma) by the high-speed photoregistration were fixed longitudinal periodic strata consisting of a layered discshaped longitudinal periodic structures of different luminosities, comprising alternating between a «light» in width $\Delta z_{h}$ (34 pcs) and the «dark» width $\Delta z_{c}$ (34 pcs) longitudinal sections. These areas formed in pairs in the discharge of said air gap with high-current circuit GPC «metallic» plasma step periodic structure EWP length about $\left(\Delta z_{h}+\Delta z_{c}\right) \approx 1.76 \mathrm{~mm}[11,15]$. One can reasonably assume that in the case of research [15] EV thin copper wires «light» longitudinal sections of the plasma «metal» products of the explosion in the discharge air gap correspond to «hot» areas of EWP, and their «dark» longitudinal sections - «cold» areas EWP. Experimental data from [15] indicate the accuracy of the quantum of provisions used in the basis of these estimations [1-9] of the wave distributions drift of free electrons and EWP respectively in thin metal conductors.

The above estimates indicate that identify in vitro particular longitudinal wave current distribution in the metal conductors can only mode transmission there through of DC, AC or pulse current $i_{0}(t)$ which provide a flow in cross sections $S_{0}$ of conductive material a relatively large current densities $\delta_{0 m}$. According to the experimental data of [16] to the DC level of density in a thin galvanized steel wire $\left(r_{0}=0.15 \mathrm{~mm} ; \Delta_{0}=5 \mu \mathrm{m}\right.$ is the thickness of the outer protective zinc coating) in an experimental study of its EWP is about $6.8 \cdot 10^{8} \mathrm{~A} / \mathrm{m}^{2}$. From own experience in the study of quantized EWP and electronic half-waves of de Broglie in a thin circular galvanized steel wire $\left(r_{0}=0.8 \mathrm{~mm} ; \Delta_{0}=5 \mu \mathrm{m}\right)$ with aperiodic pulsed axial current $i_{0}(t)$ millisecond duration in a research laboratory, equipped powerful high-voltage GPC to form a long-term load on the electric $C$ - component of artificial lightning current [12], it follows that the values $\delta_{0 m}$ numerically equal about $3.7 \cdot 10^{8} \mathrm{~A} / \mathrm{m}^{2}[3,7]$.

In connection with the above, the proposed settlement and the experimental method of research in the macrostructure selected based on visualization of the expected electro manifestations (quantized longitudinal EWP and forming their electronic half-waves of de Broglie) metallic conductor with a pulsed axial current $i_{0}(t)$ is based on the use of these quantum-physical laws and circuitry High discharge circuit of mentioned GPC- $C$ shown in Fig. 1. As test samples (TS) of the conductor to be included as shown in Fig. 1 and 2 in the high-current high-voltage circuit GPC- $C$ use the straight portions of commercially available galvanized steel wire $\left(r_{0}=0.8 \mathrm{~mm} ; l_{0}=320 \mathrm{~mm}\right.$; $\Delta_{0}=5 \mu \mathrm{m} ; S_{0}=2.01 \mathrm{~mm}^{2}$ ) [17]. The presence in such TS in a relatively thin coating of fusible and refractory enough massive wire base provides in its intensive local Joule heating (to temperatures of about $1500{ }^{\circ} \mathrm{C}$ ) indirect detection by a sphere-like swelling on the cover of «hot» sections of longitudinal wires quantized longitudinal EWP and accordingly electronic de Broglie half-waves forming such EWP [7, 9].

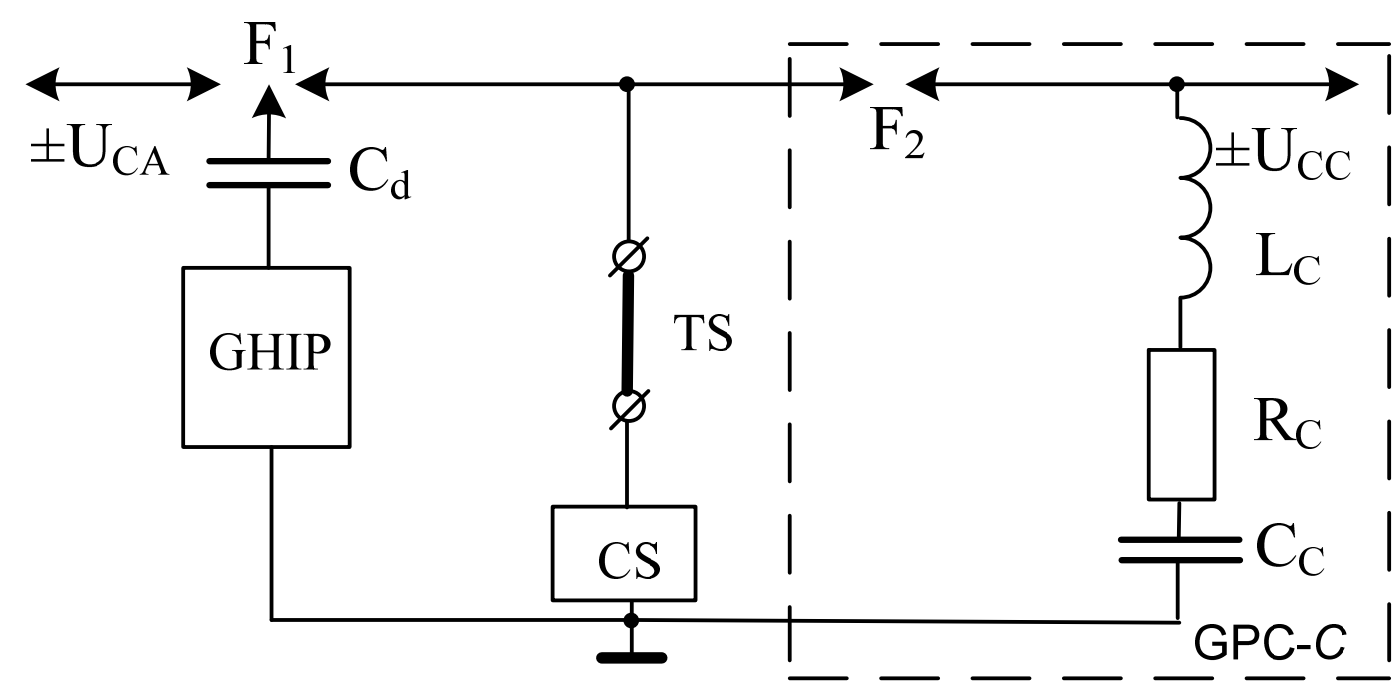

Fig. 1. Schematic diagram of high-current discharge circuit powerful high voltage GPC- $\bar{C}$ applied to the study of quantized periodic longitudinal VEP and electronic half-waves of de Broglie in the test piece of metal wire (GHIP - generator of highvoltage ignition pulses of amplitude up to $\pm 100 \mathrm{kV} ; F_{1}, F_{2}$ - respectively, three and two-electrode spark high air switches;

$C_{d}$ - dividing capacity of $180 \mathrm{pF}$ and a pulse voltage up to $\pm 120 \mathrm{kV}$ in the GHIP circuit controlling actuation air spark switches $F_{1}$ and $F_{2}$; TS - test sample of the metallic conductor; CS - coaxial shunt type ШК-300 for measurement of pulse current in the conductor; $\pm U_{C C}$ - charging voltage of capacitors GPC- $C ; \pm U_{C A}$ - charging voltage of capacitors of another GPC of existing artificial lightning current generator; $L_{C} \approx 11.43 \mathrm{mH}, R_{C} \approx 4.74 \Omega, C_{C} \approx 45.36 \mathrm{mF}$ - respectively, inductance, active resistance and capacitance of the discharge circuit of GPC-C)

Used a powerful single-module GPC- $C$ at rated stores electric energy $W_{C 0}=567 \mathrm{~kJ}$ arranged according to the scheme of Fig. 1 through 324 parallel-connected highvoltage pulse capacitors ИM-5-140 (rated voltage $U_{0}= \pm 5$
$\mathrm{kV}$; nominal capacity $C_{0}=140 \mu \mathrm{F}$ ) has the following own electrical parameters [12]: $C_{C} \approx 45.36 \mathrm{mF} ; R_{C} \approx 4.74 \Omega$; $L_{C} \approx 11.43 \mathrm{mH}$. Note that in the GPC- $C$ was applied resistive protect it from accidental over-current capacitors 
implemented by placing on their high conclusions permanent protective bulk graphite-ceramic resistors TBO-60$100 \Omega[12,18]$. After charging to constant voltage $U_{C C} \leq \pm 4.2 \mathrm{kV}$ capacitors GPC-C (at $U_{C A}=0$ ) and the supply of high voltage generator of ignition pulses (GHIP) control microsecond pulse amplitude voltage of $\pm 100 \mathrm{kV}$ high-voltage electrode is controlled three-electrode spark air switch $F 1$ cascade type hemispherical steel working electrodes and the spacing length of $4 \mathrm{~mm}$ and $9 \mathrm{~mm}$ which is part of the present at the Scientific-\&-Research Planning-\&-Design Institute «Molniya» of the NTU «KhPI» artificial lightning current generator [12], due to the TS formed wire surge pulse occurs triggering high voltage two-electrode spark air switch $F 2$ rectangular graphite electrodes and insulating the working gap of 3 $\mathrm{mm}$ in length.

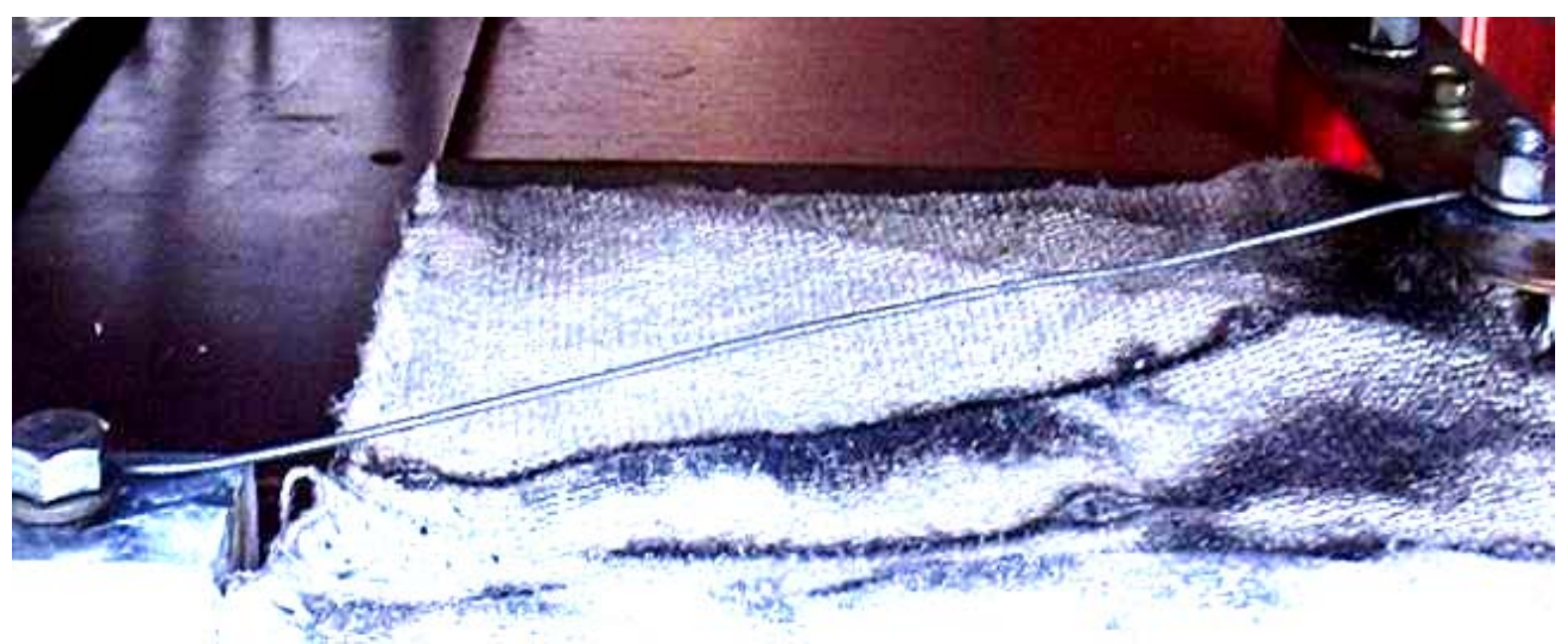

Fig. 2. General view of the continuous round galvanized steel wires $\left(r_{0}=0.8 \mathrm{~mm} ; l_{0}=320 \mathrm{~mm} ; \Delta_{0}=5 \mu \mathrm{m} ; S_{0}=2.01 \mathrm{~mm}^{2}\right)$ included its ends by means of a bolted joint in high-power high-voltage discharge circuit GPC- $C$ and placed on a thermal asbestos cloth, before subjecting it to an aperiodic pulse axial current $i_{0}(t)$ of high density

As a result, through the TS wires will flow current pulse required ATP. ATP measurement pulse wires running through the TS current $i_{0}(t)$ is performed using a digital storage oscilloscope Tektronix TDS 1012 and attorney metrological service measuring coaxial shunt (CS) ШК-300 type with its own internal resistance of 0.185 $\mathrm{m} \Omega$ and fixable nano-, micro- and millisecond current pulse amplitude of $10 \mathrm{~A}$ to $200 \mathrm{kA}$ [12], is included as shown in Fig. 1 nonpotential (grounded) part of the highcurrent discharge circuit GPC-C. We use CS at regular measurement in the discharge circuit GPC-C long aperiodic component of artificial lightning current conversion ratio was equal to approximately $56.42 \cdot 10^{2} \mathrm{~A} / \mathrm{V}[7,12]$.

Fig. 3 shows the waveform of an aperiodic pulse of negative polarity in the discharge current circuit GPC- $C$ if its TS instead of regular steel wire equivalent electrical load in the form of an aluminum sheet $2 \mathrm{~mm}$ thick and in terms $0.5 \mathrm{~m} \times 0.5 \mathrm{~m}$. It can be seen that when the amplitude of the module $I_{0 m} \approx 835$ A generated in this case $\left(W_{C} \approx 400 \mathrm{~kJ} ; U_{C C} \approx-42 \mathrm{kV}\right)$ aperiodic pulse wave current time $t_{m} / \tau_{p} \approx 9 \mathrm{~ms} / 160 \mathrm{~ms}$ ( $t_{m}$ is time corresponding $I_{0 m} ; \tau_{p}$ is the duration $0.5 I_{0 m}$ current pulse level) is characterized by a complete duration $t_{0} \approx 1000 \mathrm{~ms}$ and transfers in highcurrent discharge circuit GPC- $C$ large electric charge, whose magnitude is approximately $q_{C} \approx 191 \mathrm{C}$.

Fig. 4 shows the negative polarity in the discharge circuit GPC- $C$ waveform $i_{0}(t)$ aperiodic current pulse in the presence of its TS investigated galvanized steel wire, losing at $t \geq 380 \mathrm{~ms}$ its metallic conductivity due to intense local Joule heating and electro-thermal destruction of its structure.

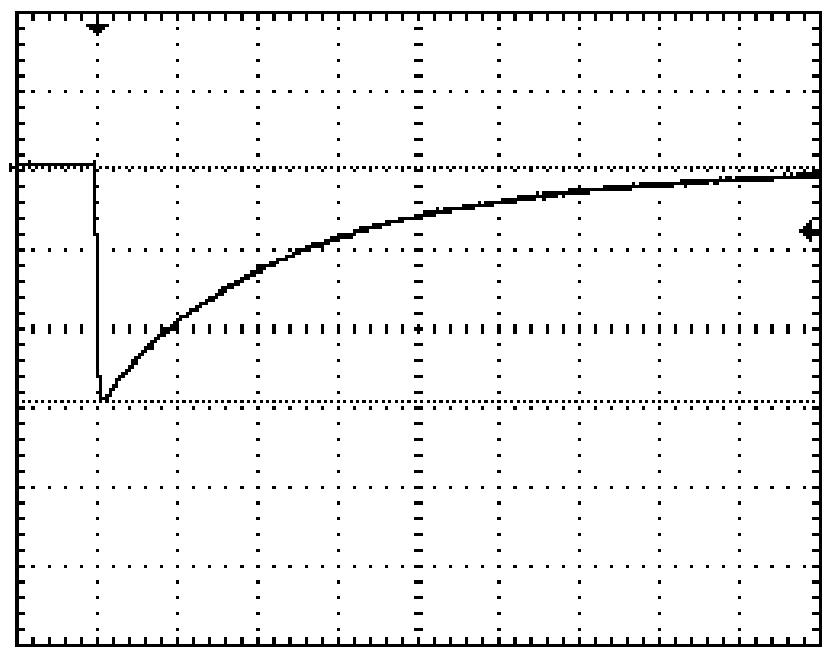

Fig. 3. Waveform of aperiodic current pulse $i_{0}(t)$ negative polarity of temporary form $t_{m} / \tau_{p} \approx 9 \mathrm{~ms} / 160 \mathrm{~ms}$ flowing in the discharge circuit GPC- $C$ with the equivalent electrical load in the form of a flat aluminum plate of $2 \mathrm{~mm}$ thick and in terms $500 \mathrm{~mm} \times 500 \mathrm{~mm}\left(W_{C} \approx 400 \mathrm{~kJ} ; U_{C C} \approx-4.2 \mathrm{kV} ; I_{0 m} \approx-835 \mathrm{~A}\right.$; $t_{m} \approx 9 \mathrm{~ms} ; \tau_{p} \approx 160 \mathrm{~ms} ; t_{0} \approx 1000 \mathrm{~ms} ; q_{C} \approx-191 \mathrm{C}$; the vertical scale $282 \mathrm{~A} /$ cell; the horizontal scale - $100 \mathrm{~ms} /$ cell)

For this reason, the total duration of the flow in the wires of the TS aperiodic current pulse temporal shape $t_{m} / \tau_{p} \approx 9 \mathrm{~ms} / 160 \mathrm{~ms}$ in our ongoing experiments did not exceed $t_{0} \approx 576 \mathrm{~ms}$. Note that the conductive structures IO wires with these TS use of current pulses is carried out under the terms of the required research the relationship between the variables $\Delta_{i}$ and $r_{0}$ [7]: $\Delta_{i} / r_{0} \approx 2 r_{0}{ }^{-1}\left[t_{m} /\left(\pi \mu_{0} \gamma_{0}\right)\right]^{1 / 2} \approx 42$, where $\mu_{0}=4 \pi \cdot 10^{-7} \mathrm{H} / \mathrm{m}$ is the 
magnetic constant [10] and $\gamma_{0} \approx 8 \cdot 10^{6} \mathrm{~S} / \mathrm{m}$ is the conductivity base metal wires used in experiments [10]. Current waveform in Fig. $4\left(W_{C} \approx 310 \mathrm{~kJ} ; U_{C C} \approx-3.7 \mathrm{kV}\right.$; $\left.I_{0 m} \approx-745 \mathrm{~A}\right)$ is a characteristic of all executed by us on GPC- $C$ experiments intense Joule heating TS galvanized steel wire, caused by weak scattering in the crystal lattice of metal atoms it electronic half-waves of de Broglie [10, 19]. Averaged amplitude of the critical current density pulse $i_{0}(t)$ as shown in Fig. 4 is not exceed $\delta_{0 m} \approx 0.37 \mathrm{kA} / \mathrm{mm}^{2}$. The experiments on the GPC-C showed that when $\delta_{0 m}>0.37 \mathrm{kA} / \mathrm{mm}^{2}$, there is a complete sublimation of the electrically conductive material of the TS steel wire, eliminating any visual observations it EWP and electronic half-waves of de Broglie [7-9].

Fig. 5-7 show external views of the TS galvanized steel wire immediately after exposure to the high-current discharge circuit in the high-voltage GPC- $C$ single aperiodic current pulse $i_{0}(t)$ of negative polarity according to the Fig. $4\left(U_{C C} \approx-3.7 \mathrm{kV} ; I_{0 m} \approx-745 \mathrm{~A} ; \delta_{0 m} \approx 0.37 \mathrm{kA} / \mathrm{mm}^{2}\right)$.

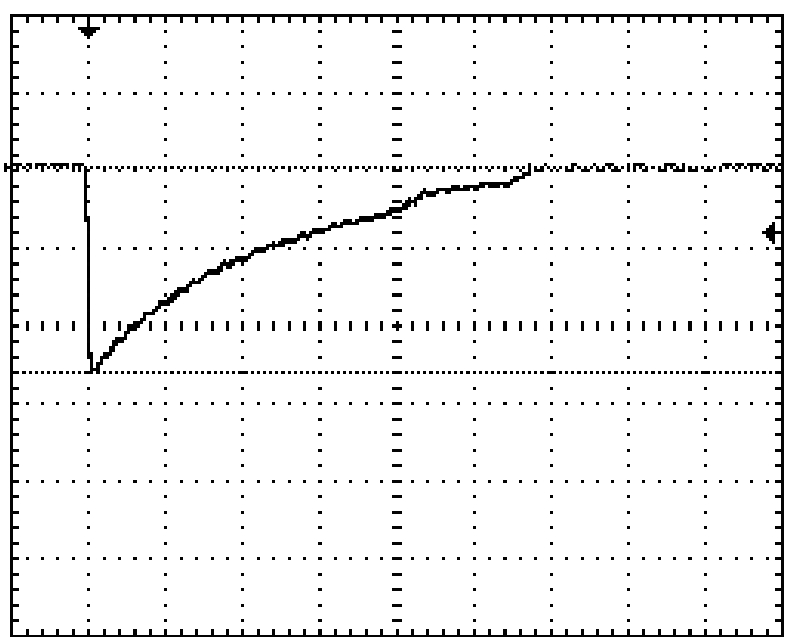

Fig. 4. Waveform of affecting the electrothermal locally destroyed analyzed straight round galvanized steel wire $\left(r_{0}=0.8 \mathrm{~mm} ; l_{0}=320 \mathrm{~mm} ; \Delta_{0}=5 \mu \mathrm{m} ; S_{0}=2.01 \mathrm{~mm}^{2}\right)$ aperiodic pulse axial current $i_{0}(t)$ negative polarity of temporary form $t_{m} / \tau_{p} \approx 9 \mathrm{~ms} / 160 \mathrm{~ms}$ of high density $\left(W_{C} \approx 310 \mathrm{~kJ} ; U_{C C} \approx-3.7 \mathrm{kV}\right.$; $\left.I_{0 m} \approx-745 \mathrm{~A} ; \delta_{0 m} \approx 0.37 \mathrm{kA} / \mathrm{mm}^{2} ; t_{m} \approx 9 \mathrm{~ms} ; \tau_{p} \approx 160 \mathrm{~ms} ; t_{0} \approx 576 \mathrm{~ms}\right)$ (the vertical scale - $282 \mathrm{~A} /$ cell; the horizontal scale - $100 \mathrm{~ms} / \mathrm{cell})$

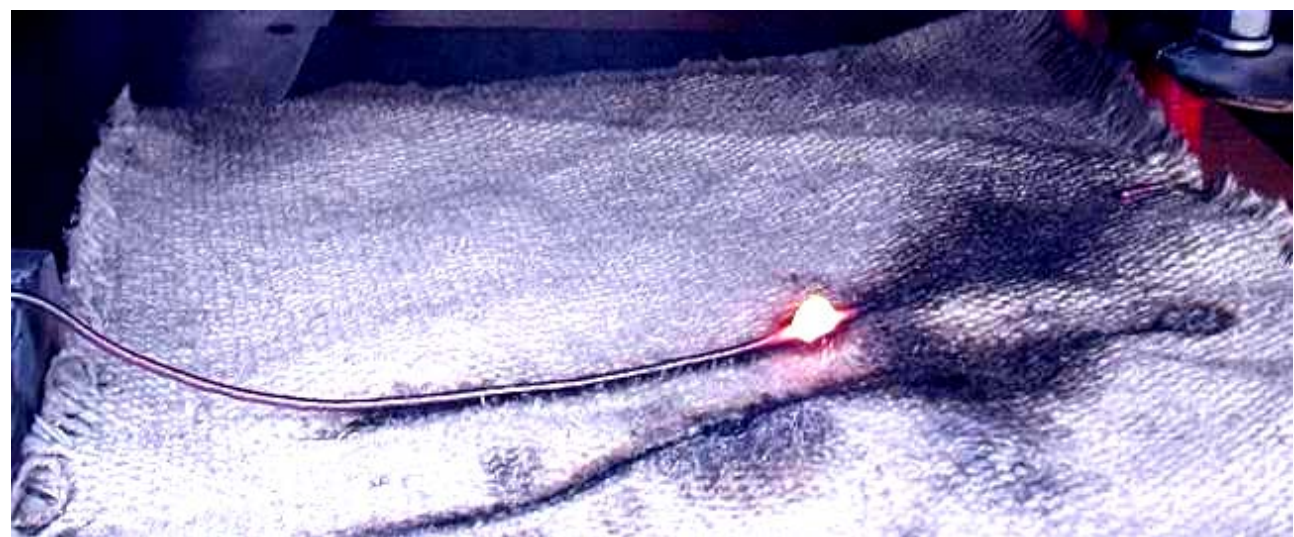

Fig. 5. External view of experimental distribution along the galvanized steel wire $\left(r_{0}=0.8 \mathrm{~mm} ; l_{0}=320 \mathrm{~mm} ; \Delta_{0}=5 \mu \mathrm{m} ; S_{0}=2.01 \mathrm{~mm}{ }^{2}\right)$ of cooling air and heatproof asbestos cloth macroscopic one «hot» (high-temperature zone width EWP $\Delta z_{n h} \approx 7 \mathrm{~mm}$ in the middle of the wire) and two extreme «cold» (width $\Delta z_{n c e} \approx 156.5 \mathrm{~mm}$ at partial sublimation of one of them) longitudinal portions after flowing through it a current pulse aperiodic $i_{0}(t)$ negative polarity temporary form $t_{m} / \tau_{p} \approx 9 \mathrm{~ms} / 160 \mathrm{~ms}$ of high density $\left(I_{0 m} \approx-745 \mathrm{~A}\right.$; $\left.\delta_{0 m} \approx 0.37 \mathrm{kA} / \mathrm{mm}^{2} ; n=1 ; t_{0} \approx 576 \mathrm{~ms}\right)[20]$

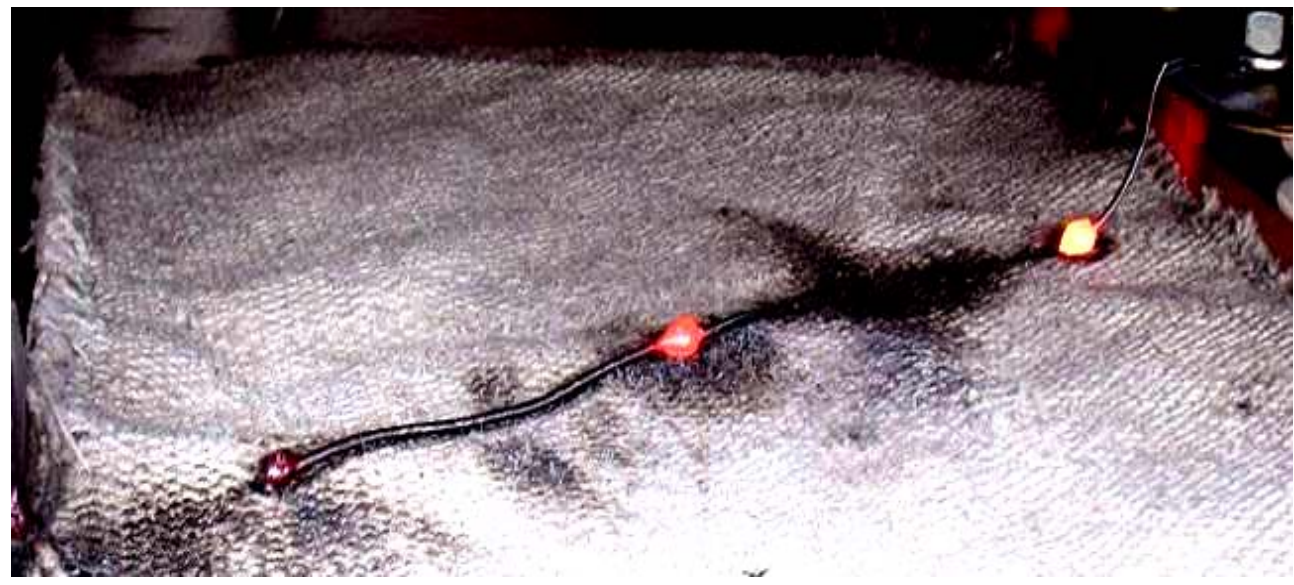

Fig. 6. External view of experimental distribution along the galvanized steel wire $\left(r_{0}=0.8 \mathrm{~mm} ; l_{0}=320 \mathrm{~mm} ; \Delta_{0}=5 \mu \mathrm{m} ; S_{0}=2.01 \mathrm{~mm}{ }^{2}\right)$ of cooling air and heatproof asbestos cloth macroscopic three «hot» (high-temperature zone width EWP $\Delta z_{n h} \approx 7 \mathrm{~mm}$ ) and four «cold» (two extreme of width $\Delta z_{n c e} \approx 50 \mathrm{~mm}$ at full sublimation of one of them and two internal of width $\Delta z_{n c i} \approx 100 \mathrm{~mm}$ ) longitudinal portions after flowing through it a current pulse aperiodic $i_{0}(t)$ negative polarity

temporary form $t_{m} / \tau_{p} \approx 9 \mathrm{~ms} / 160 \mathrm{~ms}$ of high density $\left(I_{0 m} \approx-745 \mathrm{~A} ; \delta_{0 m} \approx 0.37 \mathrm{kA} / \mathrm{mm}^{2} ; n=3 ; t_{0} \approx 576 \mathrm{~ms}\right)$ [20] 


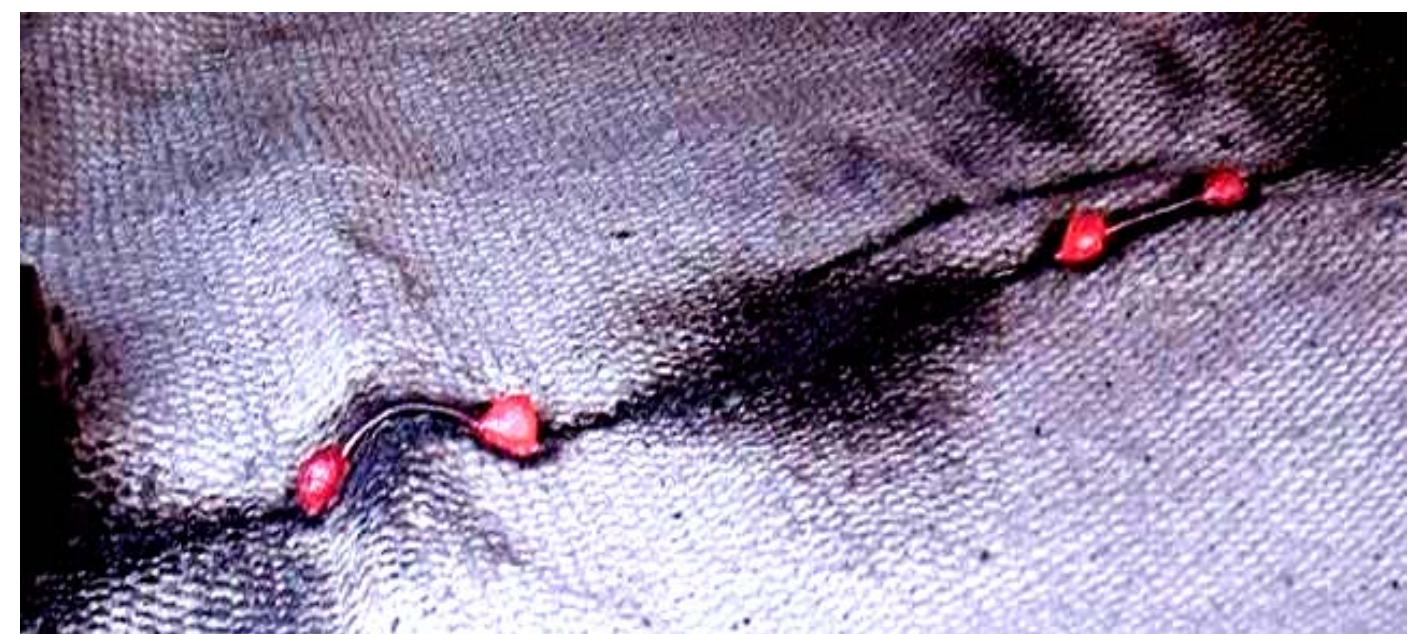

Fig. 7. External view of experimental distribution along the galvanized steel wire $\left(r_{0}=0.8 \mathrm{~mm} ; l_{0}=320 \mathrm{~mm} ; \Delta_{0}=5 \mu \mathrm{m} ; S_{0}=2.01 \mathrm{~mm}{ }^{2}\right)$ of cooling air and heatproof asbestos cloth macroscopic four «hot» (high-temperature zone width EWP $\Delta z_{n h} \approx 7 \mathrm{~mm}$ ) and two internal «cold» (width $\Delta z_{n c i} \approx 27 \mathrm{~mm}$ ) longitudinal portions after flowing through it a current pulse aperiodic $i_{0}(t)$ negative polarity temporary form $t_{m} / \tau_{p} \approx 9 \mathrm{~ms} / 160 \mathrm{~ms}$ of high density $\left(I_{0 m} \approx-745 \mathrm{~A} ; \delta_{0 m} \approx 0.37 \mathrm{kA} / \mathrm{mm}^{2} ; n=9 ; t_{0} \approx 576 \mathrm{~ms}\right.$; the other five are «hot» and eight «cold» areas of the longitudinal wires have undergone complete sublimation) [20]

Thermal state of cooling air and heatproof asbestos cloth thickness $3 \mathrm{~mm}$, made of chrysotile asbestos (its melting point is about $1500{ }^{\circ} \mathrm{C}[21]$ ), the TS of the test wire indicates a partial sublimation of the electrically conductive structures (for zinc coating melting temperature is about $419{ }^{\circ} \mathrm{C}$ and the boiling point $-907{ }^{\circ} \mathrm{C}$ [10]; for the steel base, these temperatures are about 1535 and $2735^{\circ} \mathrm{C}$, respectively [10]) and the presence of a stochastic manner arising along the galvanized steel wire from one of said impulse current exposure to other meltblown brightly glowing sphere-like quantized «entities» the same in all cases, the width $\Delta z_{n h} \approx 7 \mathrm{~mm}$.

The number of these «entities» in Fig. 5-7 corresponds to the quantum number $n=1,3,9$. Between these sphere-like «formations» that have white-hot steel and, accordingly, the temperature of not less than $1200{ }^{\circ} \mathrm{C}[7$, 16], located cylindrical «necks» in diameter $2 r_{0}=1.6 \mathrm{~mm}$ and width of quantized $\Delta z_{n c}$ with visually intact due to the pulsed heating zinc coating on them. Because of the heat indicated «necks», together with their surviving zinc coating acquired dark color.

Metallographic examination under an optical microscope МБС-9 type of cooled and carefully cleaned with a soft cloth cylindrical «isthmus» TS wires showed that they contain a uniform, shiny and adherent to a steel base wires zinc coating [7]. These experimental data indicate that the maximum heating temperature on cylindrical «isthmuses» TS wire does not exceed the melting temperature of the zinc coating (not more than $419^{\circ} \mathrm{C}$ ) [10]. With regard to the results of the survey on the optical microscope МБC-9, the cooled sphere-like «formations» TS wires inside them contained hardened fraction of the boiled and molten zinc coating steel wire base [7]. In this regard, the maximum heating temperature of the spherelike «formations» TS wire is not less than the melting point of its steel base $\left(\geq 1535^{\circ} \mathrm{C}[10]\right)$. This conclusion is confirmed by the fact that under all natural cooled air sphere-like «formations» TS wires occurred keyhole heat cloth, made of chrysotile asbestos not less than $1500{ }^{\circ} \mathrm{C}$ with a melting point [21]. The above thermal results obtained with use of a powerful high-voltage GPC-C and line segments of thin galvanized steel wire high experiments indicate that the quantized sphere-like «formations» in the TS wires correspond to the «hot» longitudinal sections of its quantized periodic longitudinal EWP and cylindrical «necks» wire in the TS - «cold» longitudinal sections of these EWP.

For the case when $n=1$ (Fig. 5), the quantized width $\Delta z_{n \times \kappa}$ each of the two extremes of «cold» longitudinal sections of the EWP, the right of which was subjected to partial sublimation, in these experiments was found to be about $156.5 \mathrm{~mm}$. The widths of these areas together with the wide $\Delta z_{n h} \approx 7 \mathrm{~mm}$ single «hot» longitudinal section EWP, located in the middle of the TS wire, according to those in [1-9] for the laws of EWP in a metallic conductor with an electrical conduction current form for the case $n=1$ the length of the quantized $\lambda_{\text {enz }} / 2$ of one half-wave electronic de Broglie, numerically equal $\lambda_{\text {enz }} / 2 \approx 2 \Delta z_{\text {nce }}+\Delta z_{\text {nh }} \approx 320 \mathrm{~mm}$. The amplitude of this halfwave electronic de Broglie corresponds to the width of the middle $\Delta z_{n h}$ «hot» longitudinal portion EWP. Obtained for $n=1$ the experimental data for the quantized longitudinal EWP and electron de Broglie half-wave in the identity of the test wire is schematically illustrated in Fig. 8,a. From (1) at $n_{e 0}=16.82 \cdot 10^{28} \mathrm{~m}^{-3}$ [10] and $\delta_{0 m}=3.7 \cdot 10^{8} \mathrm{~A} / \mathrm{m}^{2}$ we find that the estimated width of the «hot» longitudinal portion of said EWP in the test wire is about $\Delta z_{n h} \approx 5.7 \mathrm{~mm}$. The estimated width of the quantummechanical assessment of the extreme «cold» longitudinal portion of the quantized longitudinal EWP in the test steel wire can be made according to the following analytical relationships [6]:

$$
\Delta z_{n c e} \approx 1_{0} /(2 n)-0,5 e_{0} n_{e 0} h /\left(m_{e} \delta_{0 m}\right)\left[8+(\pi-2)^{2}\right] .
$$

From (2) at $n=1, n_{e 0}=16.82 \cdot 10^{28} \mathrm{~m}^{-3}$ and $\delta_{0 m}=3.7 \cdot 10^{8}$ $\mathrm{A} / \mathrm{m}^{2}$ it follows that $\Delta z_{n c e} \approx 157.1 \mathrm{~mm}$. Then, for the calculated length $\lambda_{\text {enz }} / 2 \approx 2 \Delta z_{n c e}+\Delta z_{n h}$ of electron half-wave 
of de Broglie studied in the quantum case $(n=1)$ we have: $\lambda_{\text {enz }} / 2 \approx 2 \times 157.1 \mathrm{~mm}+5.7 \mathrm{~mm} \approx 319.9 \mathrm{~mm}$. It can be seen that the results of experiments performed by highquantum case $n=1$ is fully correspond to the data of quantum-mechanical calculation of EWP in the studied steel galvanized wire.

For the case of $n=3$ (Fig. 6) $\Delta z_{n c e}$ quantized width of each of the two extremes of «cold» longitudinal portions quantized longitudinal EWP, the left of which has undergone a complete sublimation is about $50 \mathrm{~mm}$ (if the width calculated by (2) $50.5 \mathrm{~mm})$. Two internal «cold» longitu- dinal sections located in this case between the neighboring «hot» sections of the longitudinal width $\Delta z_{n h} \approx 7 \mathrm{~mm}$, had a quantized width $\Delta z_{n c i} \approx 100 \mathrm{~mm}$. It can be seen that the experimental width $\Delta z_{n c i}$ internal «cold» longitudinal sections twice the width $\Delta z_{n c e}$ experienced extreme «cold» longitudinal sections TS steel wire. Therefore, the quantum case $n=3$, the length of the quantized experienced $\lambda_{\text {enz }} / 2$ half-wave of de Broglie in TS wires will be numerically $\lambda_{\text {enz }} / 2 \approx \Delta z_{n c i}+\Delta z_{n h} \approx 107 \mathrm{~mm}$. The experimental data obtained for the quantum case $n=3$ is schematically shown in Fig. 8, $b$.

a)

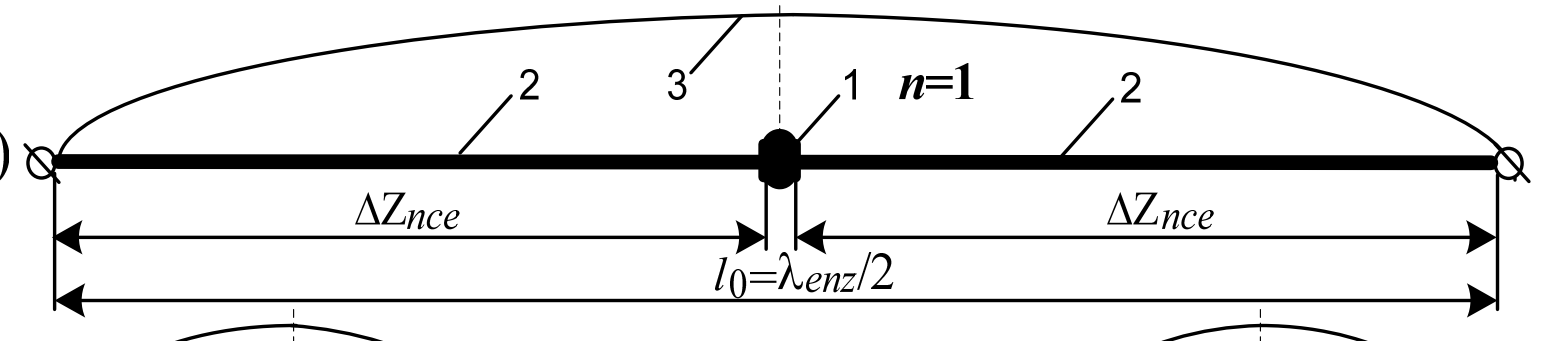

b)

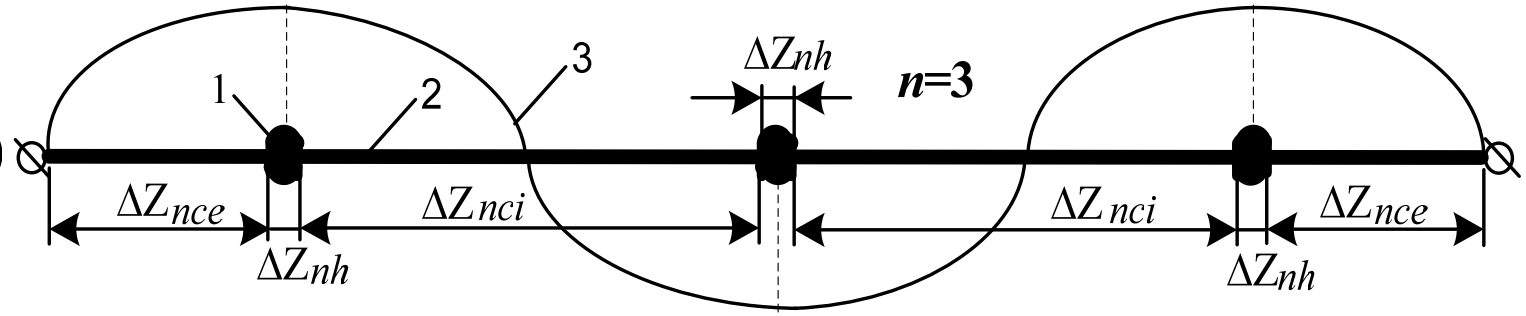

c)

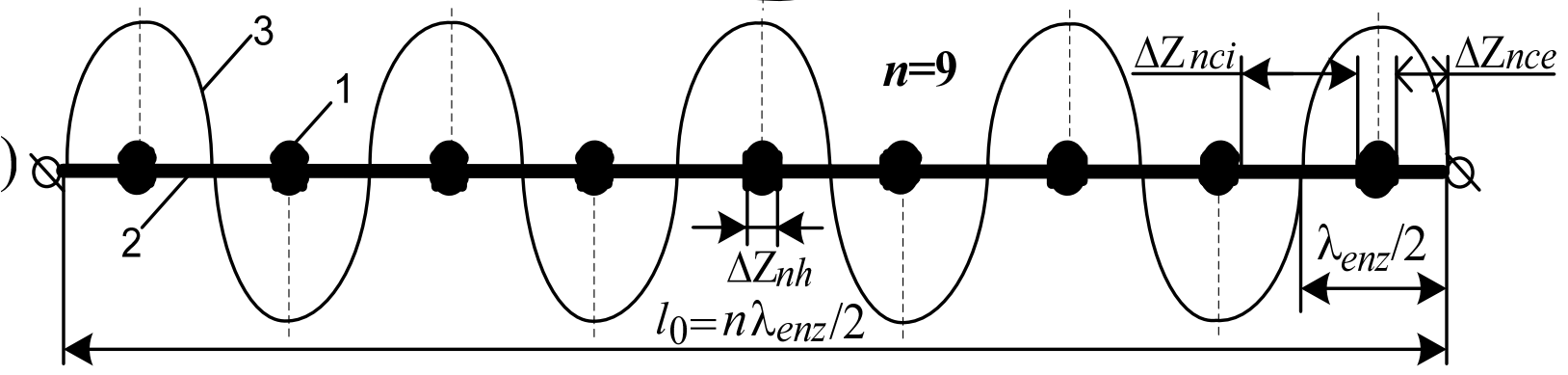

Fig. 8. Simplified schematic representation of the experimental data for the «hot» $\left(\Delta z_{n h} \approx 7 \mathrm{~mm}\right)$ and «cold» longitudinal sections quantized periodic longitudinal EWP and electronic half-waves of de Broglie in TS round galvanized steel wire radius $r_{0}=0.8 \mathrm{~mm}$ and length $l_{0}=320 \mathrm{~mm}$ experiencing in the high-voltage high-current discharge circuit GPC- $C$ single exposure time aperiodic pulse current form $t_{m} / \tau_{p} \approx 9 \mathrm{~ms} / 160 \mathrm{~ms}$ of high density $\delta_{0 m} \approx 0.37 \mathrm{kA} / \mathrm{mm}^{2}$ (1 - «hot» EWP part; 2 - «cold» EWP part; 3 - electronic halfwave of de Broglie length $\lambda_{\text {enz }} / 2$; for $a-n=1$ and $\lambda_{\text {enz }} / 2 \approx 320 \mathrm{~mm}$; for $b-n=3$ and $\lambda_{\text {enz }} / 2 \approx 107 \mathrm{~mm}$; for $c-n=9$ and $\lambda_{\text {enz }} / 2 \approx 34 \mathrm{~mm}$ )

From the estimated settlement of (1) at $n_{e 0}=16.82 \cdot 10^{28} \mathrm{~m}^{-3}$ and $\delta_{0 m}=3,7 \cdot 10^{8} \mathrm{~A} / \mathrm{M}^{2}$ width $\Delta z_{n h}$ 《hot» longitudinal portion EWP follows that it is equal to about $5.7 \mathrm{~mm}$. Settlement quantum mechanical estimate for $n=3$ width $\Delta z_{n c i}$ internal «cold» longitudinal portion EWP in the test conductor will perform the analytical relation of the form [6]:

$$
\Delta z_{n c i} \approx l_{0} / n-e_{0} n_{e 0} h\left(m_{e} \delta_{0 m}\right)^{-1}\left[8+(\pi-2)^{2}\right]^{-1} .
$$

From (3) for $n=3, \quad n_{e 0}=16.82 \cdot 10^{28} \mathrm{~m}^{-3}$ and $\delta_{0 m}=3.7 \cdot 10^{8} \mathrm{~A} / \mathrm{m}^{2}$ we obtain that $\Delta z_{n c i} \approx 101 \mathrm{~mm}$. As a result, the estimated length $\lambda_{\text {enz }} / 2 \approx \Delta z_{n c i}+\Delta z_{n h}$ electronic halfwave of de Broglie relation to the quantum case $n=3$, we find: $\lambda_{\text {enz }} / 2 \approx 101 \mathrm{~mm}+5.7 \mathrm{~mm} \approx 106.7 \mathrm{~mm}$. Therefore, we can say that the experimental results on the GPC- $C$ by indirect detection of a thin galvanized steel wire quantized longitudinal EWP and electronic de Broglie half-waves in the quantum case $n=3$, and correlate well with the calculated data.

For quantum case $n=9$ (Fig. 7) surviving «hot» EWP quantized longitudinal portions also had $\Delta z_{n h} \approx 7 \mathrm{~mm}$ width (the width when calculated according to (1) of $5.7 \mathrm{~mm}$ ). Quantized width $\Delta z_{n c i}$ internal «cold» TS in the longitudinal wire portions in this case was about $27 \mathrm{~mm}$ (when calculated on the width (3) $29.8 \mathrm{~mm}$ ). In this regard, the length of the quantized experienced $\lambda_{\text {enz }} / 2$ half-wave of de Broglie in TS galvanized steel wires for the quantum case $n=9$ is approximately equal $\lambda_{e n z} / 2 \approx \Delta z_{n c i}+\Delta z_{n h} \approx 34 \mathrm{~mm}$. Fig. 8, $c$ is illustrative in schematic form displayed corresponding experimental data for the TS considered in the case of quantum wires $(n=9)$. In this case, as in the cases with the quantum numbers $n=1$ (see. Fig. 5) and $n=3$ (see. Fig. 6), the middle «hot» longitudinal portions quantized 
periodic EWP correspond to the amplitudes TS investigated cylindrical propagated in conductive structure wire quantized coherent electron de Broglie half-waves. In view of the above data for the calculated value for $n=9$ length $\lambda_{e n z} / 2$ electron de Broglie half-wave in the TS $\lambda_{\text {enz }} / 2 \approx 29.8 \mathrm{~mm}+5.7 \mathrm{~mm} \approx 35.5 \mathrm{~mm}$ wires we have: $\lambda_{\text {enz }} / 2 \approx 29.8 \mathrm{~mm}+5.7 \mathrm{~mm} \approx 35.5 \mathrm{~mm}$. Therefore, we can say that in this quantum case $(n=9)$ experienced the results for the geometric parameters of the «hot» and «cold» longitudinal sections quantized periodic longitudinal EWP and accordingly the electronic half-waves of de Broglie in thin galvanized steel wire with aperiodic pulse current temporary form $t_{m} / \tau_{p} \approx 9 \mathrm{~ms} / 160 \mathrm{~ms}$ of high density $\left(\delta_{0 m} \approx 0.37 \mathrm{kA} / \mathrm{mm}^{2}\right)$ in the range of $4 \%$ in line with the relevant data submitted by us quantum mechanical calculation estimates for the basic geometric characteristics of EWP and de Broglie electron half-waves in the investigated steel wire.

\section{Conclusions.}

1. The proposed and tested in a high-voltage laboratory of computational and experimental method for the detection and direct determination of geometric parameters (in particular, the widths $\Delta z_{n h}, \Delta z_{n c e}$ И $\left.\Delta z_{n c i}\right)$ «hot» and «cold» longitudinal sections quantized periodic longitudinal EWP and thus indirectly determining the values of the quantized lengths $\lambda_{\text {enz }} / 2(n=1,2,3, \ldots)$ they form the electronic half-waves of de Broglie in a round galvanized steel wire $\left(r_{0}=0.8 \mathrm{~mm} ; l_{0}=320 \mathrm{~mm} ; \Delta_{0}=5 \mu \mathrm{m} ; S_{0}=2.01\right.$ $\mathrm{mm}^{2}$ ), which in a single operation from the one described in brief high-voltage high-power GPC- $C$ developed at the Scientific-\&-Research Planning-\&-Design Institute «Molniya» of the NTU «KhPI» unipolar momentum affects the axial current temporary form $t_{m} / \tau_{p} \approx 9 \mathrm{~ms} / 160 \mathrm{~ms}$ of large average density $\left(\delta_{0 m} \approx 0.37 \mathrm{kA} / \mathrm{mm}^{2}\right)$.

2 . For the first time settlement and experimentally investigated for a round galvanized steel wires, is confirmed the important fundamentals of the theory of electricity electrophysical the fact that in this metal conductor used with aperiodic pulsed axial current conduction time form $9 \mathrm{~ms} / 160 \mathrm{~ms}$ and high density (about $0.37 \mathrm{kA} / \mathrm{mm}^{2}$ ) in the longitudinal direction extend quantized coherent electronic half-wave of de Broglie length $\lambda_{\text {enz }} / 2$ defined during the investigations by the quantum numbers $n=1,3,9$.

3. The interference of de Broglie electron half-waves gives rise to the conductive structure of the investigated steel galvanized wire quantized periodic longitudinal WEP macroscopic size, mid experimentally identical fixed widths $\Delta z_{n h} \approx 7 \mathrm{~mm}$ «hot» longitudinal sections which correspond to the amplitudes of these half-waves quantized electron de Broglie length in accordance with the established contact ratio $\lambda_{\text {enz }} / 2 \approx l_{0} / n$ with $n=1,3,9$ in the 320,107 and $34 \mathrm{~mm}$, as well as an appearance in the macrostructure of the longitudinal wires inhomogeneous periodic temperature field with a temperature difference between its «hot» and «cold» longitudinal in about $1000^{\circ} \mathrm{C}$.

\section{REFERENCES}

1. Baranov M.I. Wave distribution of free electrons in conductor with electric current of the conductivities. Russian Electrical engineering, 2005, no.7, pp. 25-33. (Rus).
2. Baranov M.I. Energy and frequency specters of the free electrons conductor with electric current conduction. Russian Electrical engineering, 2006, no.7, pp. 29-34. (Rus).

3. Baranov M.I. New physical mechanisms and approaches in the study of the formation and distribution of the electric conduction current in the conductor. Tekhnichna Elektrodynamika, 2007, no.1, pp.13-19. (Rus).

4. Baranov M.I. Quantum-mechanical approach in the calculation of those temperature heating wire electric conduction current. Tekhnichna Elektrodynamika, 2007, no.5, pp. 14-19. (Rus). 5. Baranov M.I. Characteristic radial distribution of free electrons in a cylindrical conductor with varying electric current. Tekhnichna Elektrodynamika, 2009, no.1, pp. 6-11. (Rus).

6. Baranov M.I. Quantum-wave nature of electric current in a metallic conductor and some of its electrophysical macrophenomena. Electrical engineering \& electromechanics, 2014, no.4, pp. 25-33. doi: 10.20998/2074-272X.2014.4.05.

7. Baranov M.I. Features heating thin bimetallic conductor large pulse current. Elektrichestvo, 2014, no.4, pp. 34-42. (Rus).

8. Baranov M.I. Local heating of electrical pathways of power electrical equipment under emergency conditions and overcurrents. Russian Electrical Engineering, 2014, vol.85, no.6, pp. 354-357. doi: 10.3103/s1068371214060030.

9. Baranov M.I. The main characteristics of the wave distribution of free electrons in a thin metallic conductor with a pulse current of high density. Elektrichestvo, 2015, no.10, pp. 20-32. (Rus).

10. Kuz'michev V.E. Zakony i formuly fiziki [Laws and formulas of physics]. Kiev, Naukova Dumka Publ., 1989. 864 p. (Rus).

11. Baranov M.I. Izbrannye voprosy elektrofiziki. Tom 3: Teorija i praktika elektrofizicheskih zadach [Selected topics of Electrophysics. Vol. 3: Theory and practice of electrophysics tasks]. Kharkiv, Tochka Publ., 2014. 400 p. (Rus).

12. Baranov M.I., Koliushko G.M., Kravchenko V.I., Nedzel'skii O.S., Dnyshchenko V.N. A Current Generator of the Artificial Lightning for Full-Scale Tests of Engineering Objects. Instruments and Experimental Technique, 2008, no.3, pp. 401405. doi: 10.1134/s0020441208030123.

13. Orlov I.N. Elektrotehnicheskij spravochnik. Proizvodstvo $i$ raspredelenie elektricheskoj energii. Tom 3, Kn. 1 [Electrical engineering handbook. Production and distribution of electric energy. Vol. 3, Book 1. Ed. I.N. Orlov]. Moscow, Energoatomizdat Publ., 1988. 880 p. (Rus).

14. Burtsev V.A., Kalinin N.V., Luchynskiy A.V. Elektricheskiy vzryv provodnikov $i$ ego primenenie $v$ elektrofizicheskikh ustanovkakh [Electric explosion of conductors and its application in electrophysical options]. Moscow, Energoatomisdat Publ., 1990. 288 p. (Rus).

15. Sobolev N.N. The study of electrical explosion of thin wires. Journal of experimental and theoretical physics, 1947, Vol.17, no.11, pp. 986-997. (Rus).

16. Marakhtanov M.K., Marakhtanov A.M. Periodical temperature changes along steel wire length caused by electrical current. Herald of the Bauman Moscow State Technical University. Series Mechanical Engineering, 2003, no.1, pp. 37-47. (Rus).

17. Belorussov N.I., Saakjan A.E., Jakovleva A.I. Elektricheskie kabeli, provoda i shnury. Spravochnik [Electrical cables, wires and cords. Directory]. Moscow, Energoatomizdat Publ., 1988. 536 p. (Rus).

18. Baranov M.I., Rudakov S.V. Development of new charts of capacitance-resistance defense of high-voltage capacitors of powerful capacity stores of energy from emergency currents. Electrical engineering \& electromechanics, 2015, no.6, pp. 47-52. (Rus). doi: 10.20998/2074-272X.2015.6.08. 
19. Baranov M.I. Strong and weak streaming free electron scattering in metallic conductor with electric conduction current Tekhnichna Elektrodynamika, 2010, no.3, pp. 3-8. (Rus).

20. Baranov M.I. Theoretical and experimental results of research into explanation of de Broglie half-wave existence in the microstructure of an active metallic conductor. Electrical engineering \& electromechanics, 2014, no.3, pp. 45-49. (Rus). doi: 10.20998/2074-272X.2014.3.09.

21. Kuhling H. Spravochnik po fizike. Per. s nem. [Dictonary on Physics. Translated from German]. Moscow, Mir Publ., 1982. 520 p. (Rus).
M.I. Baranov ${ }^{1}$, Doctor of Technical Science, Chief Researcher, S.V. Rudakov ${ }^{2}$, Candidate of Technical Science, Associate Professor,

${ }^{1}$ Scientific-\&-Research Planning-\&-Design Institute «Molniya», National Technical University «Kharkiv Polytechnic Institute», 47, Shevchenko Str., Kharkiv, 61013, Ukraine, phone+38057 7076841, e-mail: eft@kpi.kharkov.ua ${ }^{2}$ National University of Civil Protection of Ukraine, 94, Chernyshevska Str., Kharkiv, 61023, Ukraine, phone+38057 7073438, e-mail: serg_73@i.ua

\section{Received 01.06.2016}

\section{How to cite this article:}

Baranov M.I., Rudakov S.V. Calculation-experimental method of research in a metallic conductor with the pulse current of electronic wavepackages and de Broglie electronic half-waves. Electrical engineering \& electromechanics, 2016, no.6, pp. 45-53. doi: 10.20998/2074-272X.2016.6.08. 